13

\title{
Низкопороговая полевая электронная эмиссия из двумерных углеродных структур
}

\author{
(С А.П. Возняковский ${ }^{1,2}$, Г.Н. Фурсей ${ }^{3}$, А.А. Возняковский ${ }^{4}$, М.А. Поляков ${ }^{3}$, \\ А.Ю. Неверовская ${ }^{2}$, И.И. Закиров ${ }^{3}$
}

${ }^{1}$ Санкт-Петербургский государственный технологический институт (Технический университет),

Санкт-Петербург, Россия

${ }^{2}$ Научно-исследовательский институт синтетического каучука им. С.В. Лебедева,

Санкт-Петербург, Россия

${ }^{3}$ Научно-исследовательский центр электрофизических проблем поверхности,

Санкт-Петербургский государственный университет телекоммуникаций им. проф. М.А. Бонч-Бруевича,

Санкт-Петербург, Россия

${ }^{4}$ Физико-технический институт им. А.Ф. Иофффе РАН,

Санкт-Петербург, Россия

E-mail: voznap@mail.ru

Поступило в Редакцию 16 января 2019 г.

В окончательной редакции 18 февраля 2019 г.

Принято к публикации 19 февраля 2019 г.

\begin{abstract}
Частицы многослойного графена, полученные методом самораспространяющегося высокотемпературного синтеза, предложены в качестве активного компонента катода для полевой электронной эмиссии. Показано, что данный материал позволяет реализовать новую технологию создания эффективных полевых эмиттеров с развитой поверхностью. Установлено, что на этом материале наблюдается эффект низкопороговой полевой электронной эмиссии. В импульсных электрических полях подтверждена возможность получения сильноточных электронных пучков с токами до сотен ампер.
\end{abstract}

DOI: 10.21883/PJTF.2019.09.47715.17705

Автоэлектронные эмиттеры являются базой целого ряда систем вакуумной нано- и микроэлектроники: активных элементов интегральных схем, низковольтных автоэмиссионных дисплеев, устройств СВЧ, точечных источников электронов. Неудивительно, что поиск путей создания новых полевых эмиттеров привлекает внимание многих исследовательских групп. Так, было установлено, что полевая электронная эмиссия из ряда углеродных материалов (нанографит, нанопористый углерод, плоские графеноподобные структуры, пирографит, нанотрубки) возбуждается в электрических полях на два-три порядка более низких, чем для традиционной автоэлектронной эмиссии из металлов и полупроводников [1-4]. Этот эффект получил название низкопороговой полевой эмиссии (НПЭ). Было показано, что эффект НПЭ наиболее отчетливо проявляется на графеноподобных структурах $[1,2]$. В общем случае физические параметры графеновых структур, в том числе необходимые для реализации НПЭ, зависят от методики их получения.

В настоящей работе приводятся первые экспериментальные результаты реализации эффекта НПЭ при использовании графеновых структур, получаемых карбонизацией биополимеров в условиях процесса самораспространяющегося высокотемпературного синтеза (СBC) [5].

Химические реакции в условиях СВС протекают по специфическому механизму неизотермических разветвленно-цепных процессов, для которых характер- но совместное действие двух принципиально разных ускоряющих процесс факторов: лавинного размножения активных промежуточных частиц и саморазогрева. Разветвленно-цепное воспламенение в отличие от теплового вызвано лавинным размножением активных промежуточных продуктов (свободных атомов, радикалов, а также возбужденных частиц в их быстрых реакциях с

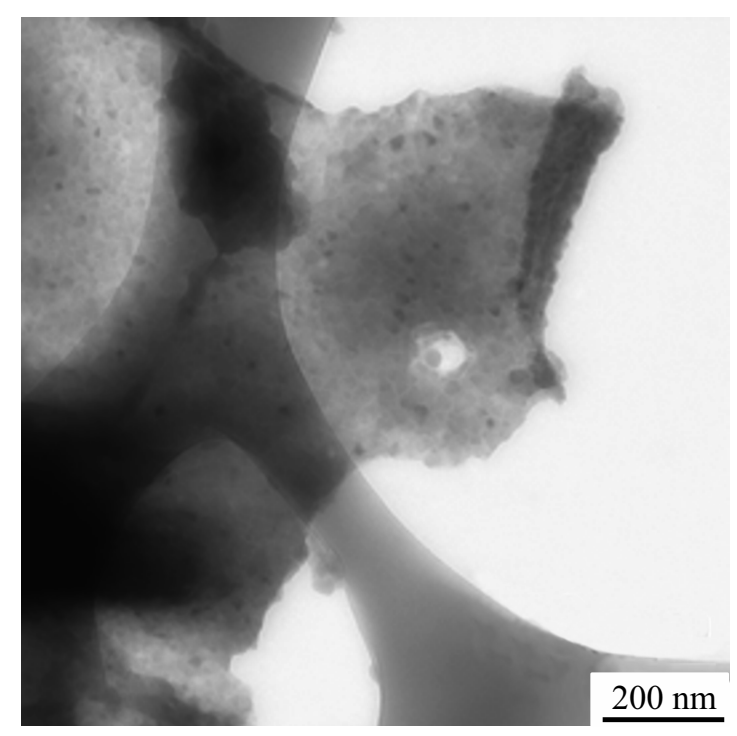

Рис. 1. Микрофотография 2D-углеродных структур в просвечивающем электронном микроскопе. 

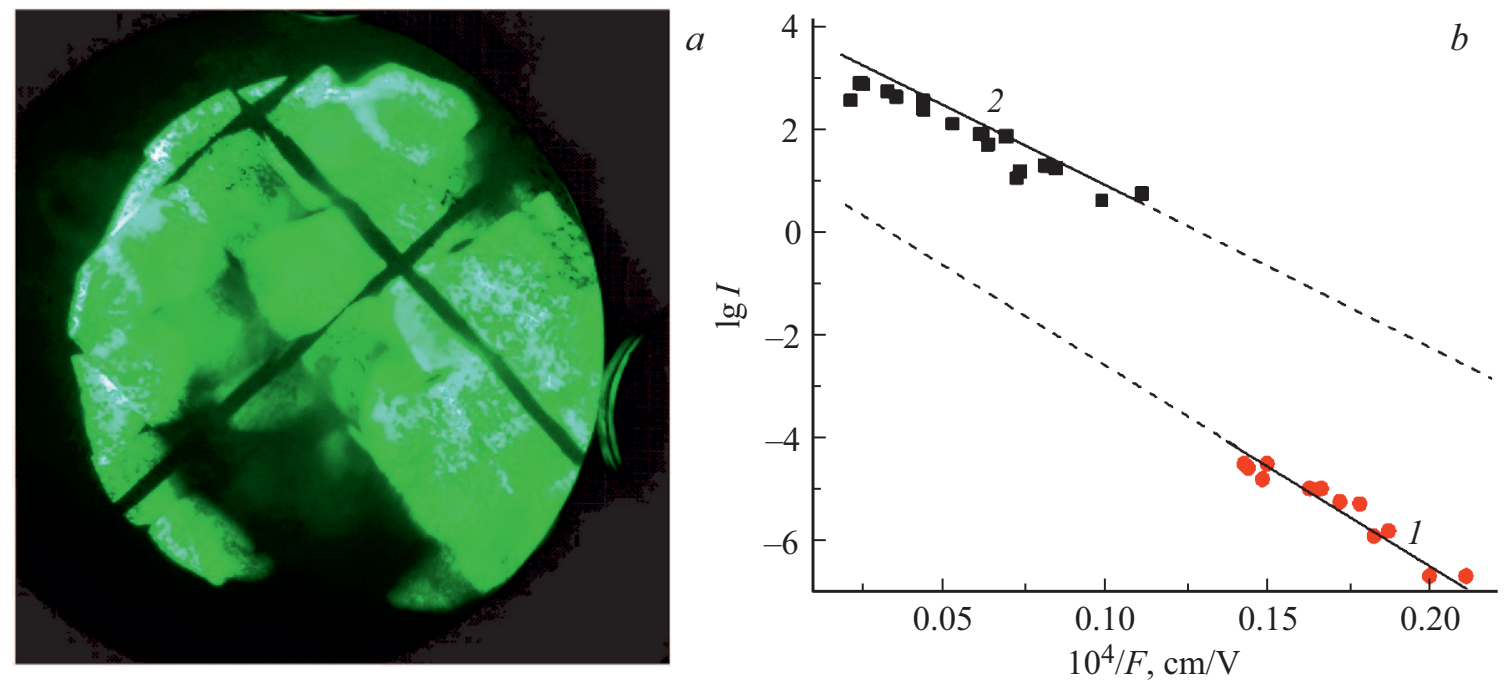

Рис. 2. $a-$ эмиссионное изображение; $b-\mathrm{BAX}$ в стационарном (1) и импульсном (2) режимах.

исходными реагентами и между собой) [6]. Физически СВС представляет собой процесс перемещения волны сильной экзотермической реакции по смеси реагентов (окислителя и восстановителя), в котором тепловыделение локализовано в слое и передается от слоя к слою путем теплопередачи. Типичными характеристиками процесса СВС являются скорость распространения фронта пламени $0.1-20 \mathrm{~cm} / \mathrm{s}$, максимальная температура горения $2300-3800 \mathrm{~K}$ и скорость нагрева вещества в волне $10^{3}-10^{6} \mathrm{~K} / \mathrm{s}$.

В результате применения процесса СВС был получен карбонизированный крахмал (SC) в виде высокодисперсного порошка. Микроструктура порошка была исследована методом электронной просвечивающей микроскопии (рис. 1). Можно видеть, что частицы SC представляют собой плоские „чешуйчатые“ структуры. Данные рис. 1, сопоставленные с данными микроскопического исследования 2D-углеродных структур, имеющимися в литературе, позволяют отнести синтезированные нами частицы SC к 2D-углеродным структурам, а именно к многослойному графену [7]. Элементный анализ, проведенный с помощью растрового электронного микроскопа, оснащенного рентгеноскопической приставкой (SEM-EDX), показал, что (в пределах чувствительности прибора) частицы SC в основном формируются атомами углерода и кислорода (91 и 9\% соответственно). Вследствие ограничения чувствительности прибора атомы водорода, входящие в состав частиц $\mathrm{SC}$, не регистрируются. Значительное количество атомов кислорода, обнаруженных в эксперименте, позволяет предположить наличие терминальных кислородсодержащих радикалов в структуре частиц SC.

Для подтверждения высказанного выше предположения о том, что в процессе используемого нами варианта карбонизации формируются именно частицы многослойного графена, а не иные возможные фор- мы наноуглерода, были проведены рентгенографические эксперименты. Вид полученной дифрактограммы полностью отвечает соответствующим кривым, получаемым на 2D-углеродных структурах — нанопластинах графена (GNP) [8]. Под нанопластинами графена понимаются образования, состоящие из нескольких графеновых слоев (2-10 слоев). Сделанный вывод согласуется с результатами, полученными с помощью рамановской спектроскопии. Общий вид спектра и расположение полос $\left(G\right.$-пик $-1500-1630 \mathrm{~cm}^{-1} ; D$-пик $\left.-1355 \mathrm{~cm}^{-1}\right)$ соответствуют 2D-графеновым структурам. Число графеновых слоев в порошке SC оценено на основе сопоставления 2D-полосы с данными работы [9] и составляет в среднем от 2 до 5. В удовлетворительном согласии со значениями, характерными для GNP, находятся также и величины удельной поверхности чатиц порошка $\mathrm{SC}$ $\left(S=120 \mathrm{~m}^{2} / \mathrm{g}\right)$ и его плотности $\left(\rho=1.910 \mathrm{~g} / \mathrm{cm}^{3}\right)$.

В качестве объекта исследования были взяты образцы $\mathrm{SC}$, полученные методом СВC из технического крахмала марки „Рerfectamyl“ фирмы „AVEBE“.

Катод представлял собой металлический цилиндр, на плоскую поверхность которого наносился тонкий слой порошка SC. Для надежного закрепления порошка на поверхности подложки использовался проводящий связующий слой. Исследования проводились в стационарном и импульсном (использовались импульсы длительностью $10 \mathrm{~ns}$ ) режимах. Вакуум при измерениях составлял $10^{-9}-10^{-8}$ Torr. Полевые эмиссионные свойства стандартно характеризуются видом эмиссионных картин и зависимости эмиссионного тока от напряженности поля. Эмиссионные изображения SC-эмиттера представлены на рис. 2,a. Можно видеть, что распределение эмиссии по поверхности катода имеет однородный характер. Эмиссионная поверхность не содержит какихлибо выраженных локальных центров. Типичная стационарная вольт-амперная характеристика (BAX), постро- 


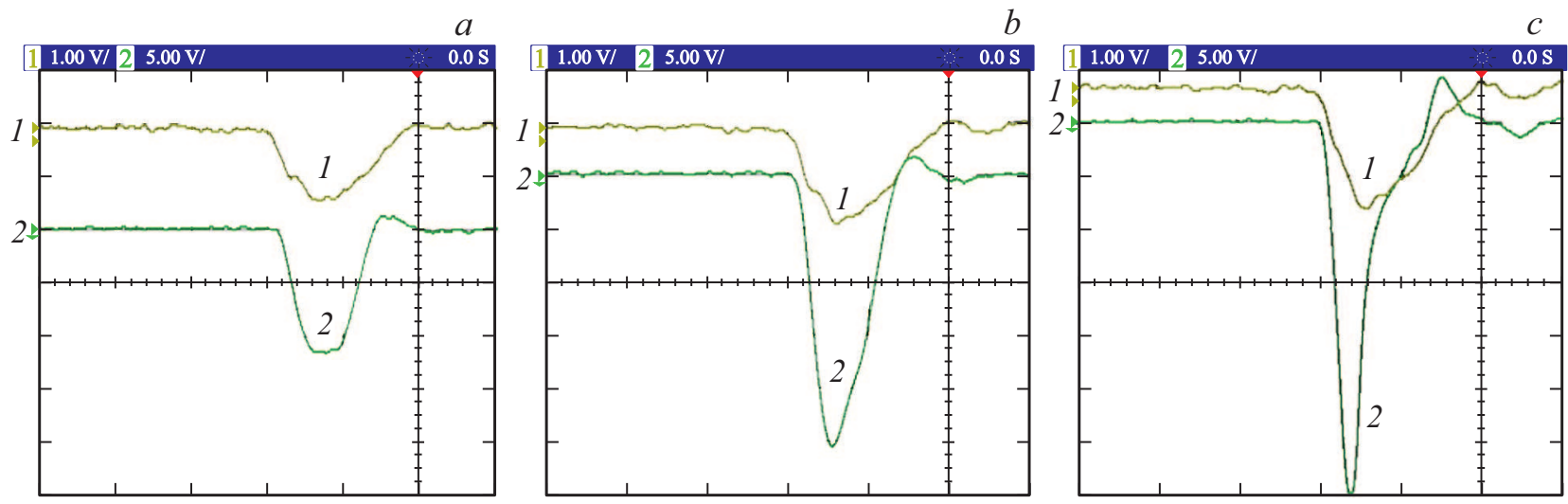

Рис. 3. Осциллограммы различных стадий $(a-c)$ изменения тока полевой электронной эмиссии с увеличением напряжения: 1 - напряжение, 2 - ток. Развертка $10 \mathrm{~ns} / \mathrm{div}$, напряжение $17 \mathrm{kV} / \mathrm{div}$, ток $200 \mathrm{~A} / \mathrm{div}$.

енная в координатах Фаулера-Нордгейма, представлена на рис. 2, $b$. Линейный вид характеристик свидетельствует о том, что зависимость тока от напряжения имеет экспоненциальный характер. Считаем необходимым особо отметить, что, несмотря на то что эта зависимость имеет внешнее сходство с закономерностью ФаулераНордгейма, она таковой не является.

В случае углеродных нанокластеров экспоненциальный характер зависимости эмиссионного тока от поля не связан с непосредственным туннелированием электронов из твердого тела в вакуум, а определяется изменением структуры и свойств углеродного эмиттера в электрическом поле [3]. В частности, как было замечено в работе [3], это изменение свойств может быть связано с расслоением графита в сильном электрическом поле. B SC-материале мы уже исходно имеем дело с разделенными углеродными слоями в результате СВС.

Пороговое значение электрических полей, при которых возникает полевая эмиссия, в случае SC составляет всего $1 \mathrm{~V} / \mu \mathrm{m}$ (для сравнения для металлов необходимы значения $\left.10^{3} \mathrm{~V} / \mu \mathrm{m}\right)$. Этот результат для SC подтверждает полученный ранее для графеноподобных структур [2,3]. Дополнительная информация была нами получена при изучении эмиссии в сильных электрических полях с применением наносекундной техники. Применение наносекундной техники позволяет продвинуться в область полей $10-100 \mathrm{~V} / \mu \mathrm{m}$. Кривая зависимости $I(F)$ в импульсных полях представлена на рис. $2, b$. Зависимость эмиссионного тока от поля, так же как и для стационарного случая, имеет линейный характер. Обращает на себя внимание параллельное смещение импульсных BAX в область больших токов. Эта закономерность связывается нами с увеличением числа эмитирующих центров, количество которых растет с ростом электрического поля. Величины токов, полученных в импульсных полях, достигают сотен ампер (рис. 3). Характерной особенностью эмиссионного процесса в импульсных полях является обнаружение эффекта „истощения“. При определенных значениях эмиссионного тока импульс тока начинает укорачиваться, и это „истощение“ (укорочение) прогрессирует с ростом поля и соответственно отбора эмиссионного тока (рис. 3). Такое истощение тока мы связываем с ограниченной величиной заряда в приповерхностной области графеноподобного эмиттера [3].

Таким образом, в работе показано, что графеновые наночастицы, полученные в процессе СBC, успешно могут быть применены в качестве активного компонента катода в вакуумной электронике. Установлено, что СВС-технология позволяет высокопроизводительным способом создать эффективные низкопороговые полевые эмиттеры.

\section{Финансирование работы}

А.П. Возняковский и А.Ю. Неверовская благодарны за финансовую поддержку в рамках гранта 18-2924129мк. Работа А.А. Возняковского выполнена в рамках государственных тематических исследований ФТИ им. А.Ф. Иоффе по теме № 0040-2014-0013.

\section{Список литературы}

[1] Фурсей Г.Н., Поляков М.А., Кантонистов А.А., Яфясов А.М., Павлов Б.С. // ЖТФ. 2013. Т. 83. В. 6. С. 71-77. DOI: $10.1134 / \mathrm{S} 1063784213060121$

[2] Fursey G., Polyakov M., Zakirov I. Phenomenon of pulsed high-power electron emission from graphene-like structures and carbon nanotubes stimulated by electric field // 2016 14th Int. Baltic Conf. on atomic layer deposition (BALD). IEEE, 2016. P. 47-52. DOI: 10.1109/BALD.2016.7886535

[3] Bandurin D.A., Mingels S., Kleshch V.I., LützenkirchenHecht D., Müller G., Obraztsov A.N. // Appl. Phys. Lett. 2015. V. 106. N 23. P. 233112. DOI: $10.1063 / 1.4922550$

[4] Архипов А.В., Габдуллин П.Г., Гнучев Н.М., Давыдов С.Н., Крель С.И., Логинов Б.А. // Науч.-техн. ведомости СПбГПУ. Физ.-мат. науки. 2015. № 1 (213). С. 77-92.

[5] Voznyakovskii A.P., Neverovskaya A.Yu., Otvalko Ja.A., Gorelova E.V., Zabelina A.N. // Nanosystems: physics, chemistry, mathematics. 2018 . V. 9. N 1. P. 125-128. DOI: $10.17586 / 2220-8054-2018-9-1-125-128$ 
[6] Азатян В.В. // Успехи химии. 1999. Т. 68. В. 12. С. 1122 1141.

[7] Stankovich S., Dikin D.A., Piner R.D., Kohlhaas K.A., Kleinhammes A., Jia Y., Wu Y., Nguyen S.T., Ruoff R.S. // Carbon. 2007. V. 45. N 7. P. $1558-1565$.

DOI: 10.1016/j.carbon.2007.02.034

[8] Stobinski L., Lesiak B., Malolepszy A., Mazurkiewiczc M., Mierzwa B., Zemek J., Jiricek P., Bieloshapka I. // J. Electron Spectr. Rel. Phenom. 2014. V. 195. P. 145-154. DOI: $10.1016 /$ j.elspec.2014.07.003

[9] Ferrari A.C., Meyer J.C., Scardaci V., Casiraghi C., Lazzeri M., Mauri F., Piscanec S., Jiang D., Novoselov K.S., Roth S., Geim A.K. // Phys. Rev. Lett. 2006. V. 97. N 18. P. 187401. DOI: 10.1103/PhysRevLett.97.187401 